\title{
Stop hitting the woodwork! CRM for better fan-identification in Romanian second division football clubs
}

\author{
Vlad ROȘCA \\ The Bucharest University of Economic Studies, Bucharest, Romania \\ vlad.rosca@fabiz.ase.ro
}

\begin{abstract}
According to pundits, Romanian football is at an unprecedented low in terms of sporting quality and fan followship altogether. A mix of mismanagement and public regulations have transformed football clubs into under-financed organizations, unable to groom their academic work, raise quality players and, subsequently, perform at highest level which ultimately led to a decrease in entertainment on the pitch and of the numbers in attendance. Adding to this is the loss of brand identity that has created a rupture between clubs and their fan-bases. The paper aims to look at customer relationship management principles that lowerleague clubs can use to build better fan relationships, while also identifying, using the same CRM optic, what actually led to the decline in quality. Second tier football has been chosen as opposed to top-flight because it consists of several clubs with development potential within their municipalities, because some of their problems are more stringent than in the upper league and, last but not least, in many cases, total attendance per game is as low as 50-300 people. The research starts with a general presentation of customer relationship management. In order to prepare CRM's adaptation to the business of professional sports, some focus will be set on the services industry. The article then presents how CRM can be applied to sports, and, in the end, it narrows down to the specific case of Romanian football by starting the investigation from some of the challenges currently faced by the sport. Particular attention is granted to the online environment, as the latter one is host to a wide range of not very expensive CRM strategies and tactics that clubs can use, cost being a factor to be taken into account for a sector with scarce monetary resources. Last but not least, the paper ends with a set of recommendations as well as future ideas for research.
\end{abstract}

Keywords: football marketing, fan relationships, matchday experience, gameday, sports business.

\section{Introduction}

Customer relationship management (CRM) is a subset of marketing used to help brands enhance their relations with clients and empower the latter ones to take proactive decisions with regards to affiliation or purchase (Pries and Stone, 2004). CRM is seen as a determinant of competitiveness because it tries to leverage the knowledge and emotions of customers after having engaged them on a long-term winwin relationship (Karakostas et al., 2005). Operationally, CRM can be regarded as the process of creating and maintaining a connection between brand-owner and brandfollower grounded in common values and interests with the goal of retaining customers.

There are several notions that literature brings into discussion when addressing the topic of successful CRM, such as customer equity, preference of choice, retention and continuity. At a first stage, with the development of information systems and technologies, CRM moves into a "social" era of value creation, where customers can be regarded as co-creators of brand value: the interaction with the company allows customers to contribute with their own meaning to the brand value 
(Labrecque, 2014; Song et al., 2016). At a first step, customers are allowed to bring their own input to how brands perform and are being judged, such a stance being of particular importance in service-based industries, where the customer interaction occurs directly with the brand, not through a tangible good (Cambra-Fierro et al., 2017; Zhang et al., 2016). A brand's value is to be judged by the quality of complex acts through which the brand answers customer demands and needs (Bruhn et al., 2014). The points of contact that represent the brand and with which the customer interacts will ultimately create the customer equity. While the core offering is the service that the customer buys and consumes, CRM steps into play and gathers under its umbrella the set of adjacent services or interactions that allow the main service to be performed. These are the critical tasks that need to be undergone in order to reach the point of actual service consumption, and can include communication, attitude or professionalism of personnel that the customer meets on the route upon enjoying the service, as well as after the service delivery. As a matter of fact, the actual service performance is only the core part of an entire service experience which is the attribute of CRM. As such, CRM has got a direct impact on the way in which the quality of a provided service is estimated by its recipients (Nyadzayo and Khajehzadeh, 2016).

Research has shown that the way in which point of contact personnel interacts with customers, as well as the promptitude of answers delivered to them, influence preference of choice and purchase decisions (Ghazian et al., 2016). Addressing customers in a kind manner has the grace to build an intimacy between brand and customer. The psychological aspect of intimacy has been studied by Bügel et al. (2011), who consider that such familiarity is one of the two components that make up for the breeding ground of CRM, next to commitment. The authors also go on to mention that intimacy with the services provider is seldom met and usually only in market sectors where customers are highly involved in the product purchase, such as the automotive or housing sectors.

Under such circumstances, customer equity becomes a mix between core service and CRM experience. The better the service delivery and the neater the intimacy between consumer and provider, the higher the chances to achieve the customer's loyalty and accomplish continuity (Zablah et al., 2004). Value creation for an organization is hardly the result of a single consumption experience, but depends on customer reliability and his continuous return to the organization for repurchasing / re-consuming the services (Niemimaa, 2017).

One of the assets that gains increasing weight in the provision of the global services experience is the online cyberspace, a platform that brands can use for easily reaching out to their customers, at high speed, high penetration rate, and rather low costs compared to on-premise marketing tactics (Wang et al., 2013). At a larger scale, using IT for conducting CRM can have two major objectives: emotional attachment and monetization. At subsequent stages, IT can lead to better sales figures if the relationships that are being created are correctly handled (Ahearne et al., 2007; SanMartín et al., 2016). Prior to this, though, successful business relationships have to start from creating positive connections between a brand and its clients.

The online environment has got several characteristics that can help brands create intimacy with customers. Once, with no closure hours existing, it can be used 
anytime, guaranteeing the continuity of the interaction between brand and customer. Lee and Kwon (2011) argue that intimacy is a result of the quality of emotions that have been accumulated over time, so the more possibilities a consumer has got to interact with the beloved brand, the better for the relationship between the two. Brands that want to tap on the opportunity of closing the gap to their customers have to try to identify and create online opportunities to encourage repetitive usage.

PICBE $\mid 713$

\section{e-CRM in football}

If regarded as an entertainment act performed by athletes, the football game is an offering consisting of a core service (the match itself) and adjacent services building up the entire matchday experience. As a service delivered to fans, football is suitable for customer relationship management, since fans evaluate the football brand based, once, on the quality that they perceive is being demonstrated to them by the footballers on the pitch and, second, by their experiences within the entire matchday, i.e. the global service (Clemes et al., 2011). While in sports success alternates with defeats, the image of a football brand is constantly scrutinized by the fans making their own "should-is" evaluations: fans expect their favorite team to win repeatedly. Expectations are high and will probably be betrayed at the moment when defeat comes into way, which will lead to fans criticizing the team and shedding a negative light onto the brand. The longer the losing-streak, the more powerful the impact on brand perceptions.

Football clubs can employ CRM to either tap on successful series or to combat negative series. In case of defeats, CRM has to maintain a positive relationship with fans and try to avoid or minimize negative brand associations. Customer relationship efforts target to improve fan identification and the creation of positive associations with the football brand (Gide and Riad Shams, 2011).

Since the main point of contact with a football brand is the matchday experience that the fan has, it is of high importance that football clubs improve their CRM capabilities around the football game, because not only the sporting result has an influence on fan perceptions, but also the entire experience around visiting a game, including the ride to the stadium, the ticketing experience (prices and ease of getting hold of tickets), the entrance to the venue, stewardship, catering and other bystanding services that can be offered in order to help fans have a positive day out at the game. e-CRM should be added into the matchday experience, but should also be kept ongoing throughout the rest of the non-matchdays in order to continuously build momentum.

CRM in football is also striving for fan retention. Bad results or negative experiences at the stadium can keep fans back from returning to the stadium. In such crisis situations, CRM communication should be employed to prevent fans detaching from supporting the club. Fans loyal to the football brand not only transform into numerous crowds coming to the stadium, but also improve stakeholder relationships and revenue streams of the club. While shifting the attention towards fans is an imperative for success, Romanian football is witnessing dramatic losses in spectatorship. A declining interest of fans leads to many matches being played in front of nearly empty stadiums. Some of the reasons of such rupture are, first of all, a loss of identity that has warded off the fans, as well as a diminished interest shown by clubs 
in approaching their fans and entering into long-term relationships with them. This reality contradicts the CRM theory, according to which football clubs have to closely keep in touch with their fans and strive to build an uninterrupted communication flow. The ongoing process should become an imperative of local football management, especially since the costs of doing marketing are low and considering the psychological benefits of football fandom.

PICBE | 714

Psychology is a factor of high importance in football, with fans being deeply emotionally bound to the team they support. As opposed to hard goods, competition is nearly inexistent: fans do not switch allegiance from one club to another, but usually follow their beloved team throughout their lives (Robinson, 2012). Such a devotion can be translated through the familiarity and commitment that Bügel et al. (2011) mention as important determinants for CRM. Being highly involved in following their favorite teams, the fans are expecting the football clubs to communicate with them via online. While in many instances hard goods manufacturers try to push their productrelated communications to the customers, team sports benefit of a "push and pull" strategy, whereby not only that the sports clubs are sending out their messages to the fans, but the fans themselves are eager to be kept up to date with the latest news and are expecting the club to reach out to them with new information. This open attitude of fans should represent a benefit for the clubs who do not need to spend extra efforts for bringing the audience in a desired state of reception. The audience is already there, expecting to receive communications.

\section{Methodology}

A model containing four variables has been developed to measure the attractiveness of e-CRM employed by the 20 football clubs taking part in the Romanian Second Division (Liga2), 2016-2017 season. Starting from the findings of the literature review, the research method aims to find out to what extent football clubs communicate to their fans and how they try to establish positive CRM relationships through the online environment.

The simplicity of the model can be explained through the fact that it took into consideration only a couple of low cost e-CRM tactics, easy to employ, which can be used by the targeted football clubs, all of them lower league clubs lacking budgets and media exposure to set too high digitalization standards. The model analyses if and how each of the 20 clubs that have started the 2016-2017 Liga2 season uses their website and Facebook pages. A club receives 1 point if it has a website, or 0 if it doesn't. The same applies for the Facebook page. Another variable inserted is the updating of these two electronic instruments: 1 point was given if the site or the social media page has been updated at least once over the last two weeks at the moment of gathering the raw data. The "Update" variable was inserted because the research is not only interested in owned media, but also how these media instruments are being used: if their capabilities are really used at a maximum in order to close the bonds to the fans. 


\section{Results}

Research results displayed in Table 1 show that there are eight clubs that use their website and Facebook at a frequent rate, six that range at a medium rate, five at a low rate and one that does not use the instruments at all. At an empirical look it can be observed that the clubs that use the power of online at its utmost are clubs with rich local traditions, such as UTA Arad, FC Brașov, Dunărea Călărași, Dacia Unirea Brăila, while at the other end we can find clubs with lower significance for the communities they represent: Metalul Reșița, CS Balotești, ACS Berceni.

Table 1. Usage of e-CRM in Liga 2 football

\begin{tabular}{|r|l|c|c|c|c|c|}
\hline \multicolumn{1}{|c|}{ Club } & Website & Updated & Facebook & Updated & Total \\
\hline 1 & Juventus Colentina & 0 & 0 & 1 & 0 & 1 \\
\hline 2 & UTA Bătrâna Doamnă & 1 & 1 & 1 & 1 & 4 \\
\hline 3 & FC Brașov & 1 & 1 & 1 & 1 & 4 \\
\hline & $\begin{array}{l}\text { Sepsi OSK Sf. } \\
\text { Gheorghe }\end{array}$ & 0 & 0 & 1 & 1 & 2 \\
\hline 5 & Olimpia Satu Mare & 1 & 0 & 1 & 1 & 3 \\
\hline 6 & CS Mioveni & 1 & 1 & 1 & 1 & 4 \\
\hline 7 & Chindia Târgoviște & 0 & 0 & 1 & 1 & 2 \\
\hline 8 & Luceafărul Oradea & 1 & 0 & 1 & 1 & 3 \\
\hline 9 & Foresta Suceava & 0 & 0 & 1 & 0 & 1 \\
\hline 10 & Dacia Unirea Brăila & 1 & 1 & 1 & 1 & 4 \\
\hline 11 & CS Afumați & 1 & 1 & 1 & 1 & 4 \\
\hline 12 & Dunărea Călărași & 1 & 1 & 1 & 1 & 4 \\
\hline 13 & Academica Clinceni & 0 & 0 & 1 & 1 & 2 \\
\hline 14 & CSM Râmnicu Vâlcea & 1 & 1 & 1 & 1 & 4 \\
\hline 15 & ASU Poli Timișoara & 1 & 1 & 1 & 1 & 4 \\
\hline 16 & CS Balotești & 0 & 0 & 1 & 0 & 1 \\
\hline 17 & Unirea Tărlungeni & 1 & 0 & 1 & 0 & 2 \\
\hline 18 & Metalul Reșița & 0 & 0 & 0 & 0 & 0 \\
\hline 19 & Șoimii Pâncota & 0 & 0 & 1 & 0 & 1 \\
\hline 20 & ACS Berceni & 0 & 0 & 0 & 0 & 0 \\
\hline
\end{tabular}

Source: Authors' own research.

The fact that clubs with rich local traditions and significance are using the online environment for forging relationships with their fans can be explained through the need of continuity. Arad, Brașov, Călărași or Brăila are important regional centers with historical fan bases. In spite of changing consumer habits and a worrying declining number of new fans, the existing relationships have to be maintained and developed. At the other end are the clubs with low significance for their fans, where fan interest does not really exist, which is also reflected in poor CRM.

The research results show rather disappointing CRM performances of second division clubs in Romania. It could be easily expected from Internet and Facebook pages to be a minimum that the clubs take care of for forging solid relationships with their fans. Nevertheless, there are many clubs that do not have a wepage, some of 
them neither a Facebook account, while those who have do not always update their accounts with new information. The common interests that fan groups share about their favorite teams and which could help in creating strong relationships are rather ignored. Second division clubs do not encourage their fans to co-create value, through not offering them adequate online platforms to exchange digital content.

One of the striking examples is Juventus Colentina who, at the moment of conducting the research, was the leader of the competition, playing good football and holding chances of promoting to Liga 1 . Nevertheless, despite a wealthy budget and a collection of characteristics that make the club stand out to its competitors (e.g. offering matchday tickets and programmes of high graphic and content quality, as well as having one of the best academies in Bucharest), Juventus did not manage to set up a marketing team for their online channels, although it was one of the goals that the management publicly announced at the beginning of the season. In conjunction with the good sporting performances and the positive matchday experiences provided at the stadium, a better online marketing presence could have improved the club's relationships with the fans, especially since Juventus Bucharest is an example of a district clubs, located in Colentina, one of Bucharest's most crowded neighborhood, having the potential to attract high numbers of followers. Their repeated successes could have also meant powerful and positive content to distribute via online.

Other clubs with poor online CRM are Unirea Tărlungeni (2 overall score), Metalul Reșița (0) and ACS Berceni (0). This comes as no wonder as all of the three have been relocated from their cities of origin in small local communities at the outskirts of Bucharest (Ștefănești, Snagov, Buftea), in the first two cases several hundreds of kilometers away from their fan base. Under such circumstances, the fans did not follow their clubs anymore and the relationships were broken, while the "destination" fans were not interested in embracing a "foreign" club. With no followship, online communication did not have any target.

Several other clubs from the outskirts of Bucharest manage their online content more or less appropriate, a positive example being CS Afumați, who has both the website and social media platforms (including YouTube), permanently updated with meaningful content, videos and images. Academica Clinceni does not have a website, but tries to relate to fans via Facebook, while CS Balotești uses Facebook but with updates.

Nine of the twenty analyzed clubs do not have a website, while several others do not use it at its full potential. Unfortunately, lower division clubs have not yet established a habit of communicating with their fans via online. At the same time, with the emergence of social media, internet pages have lost importance, with followers shifting mainly to Facebook. Social media has still got untapped opportunities for approaching fans. Also striking to find out after conducting the research is that teams in cities with great socio-economic importance such as Târgoviște, Suceava or Oradea are yet to have reached out to their potentially massive local support. A positive example in this regard is Sepsi OSK, a team located in the town of Sf. Gheorghe, who in spite of not having a website, has managed to move the electronic communication to Facebook. After having played the first half of the championship, Sepsi OSK was third at average spectator numbers in the entire league after Suceava and Târgoviște (31\% avg. sell-out and 1560 avg. attendance). This performance is, amongst others, a result 
of the good relationships that the club has forged with its fans. Sepsi OSK is one of the few clubs to organize regular fan meetings, many of them in the club-branded dedicated fast-food restaurant which serves menus named after the club's assets, and also amongst the few clubs to organize shuttle trips for fans who wish to support their club at away matches. Next to these, the club sells general admission tickets for 10 Lei per game, offering a free matchday programme with the ticket. Next to these successful CRM tactics, Sepsi OSK benefits of rich local media coverage, as well as it has an own Facebook page, constantly updated with relevant content. Next to this, a powerful fan-page rich in updates also contributes to the approach between club and fans.

In terms of CRM goals, these are hardly achieved. While even updating fans with relevant information is a struggle for many clubs, fan-created equity is nearly inexistent. Apart from Poli Timișoara and UTA Arad, which are clubs run by fangroups, most of the other clubs do not make the necessary efforts to encourage their fans to create and distribute online media content through which value for the football brand may be raised. Galuszka (2015) discusses about a "new economy of fandom", where brand owners should empower their fan communities to use social media, in order to draw benefits from them. Benefits can be either monetary or emotional. An emotional benefit would be allowing the fans to co-create value for the football brand by producing meaningful content which to be distributed online. Promoting hashtags (\#) that fans could use to identify their beloved football brand when posting their photos and videos online might help in raising brand awareness. Once they have attracted fans to the online environment, clubs should aim at a deeper engagement level that would involve retaining those fans through special loyalty programs. That would start as on online task but would ultimately have to be doubled by efforts of meeting fans face to face and encouraging them to come to the stadium. While preference of choice should be a given, considering fans have already decided what team to support, clubs need to use CRM in order to attract fans in the competition with rival entertainment offerings (i.e. influence fans to come to the stadium instead of other leisure activities). Retention and continuity are also goal to be improved, especially since the potential fan base is larger than what the football clubs have managed to reach online.

\section{Conclusion}

This research has provided a surface look over how football clubs in the Romanian Second League use the power of online in order to get in contact with their fans. On a general note, the main idea would be that there is still plenty of room for improvement. In spite of new technologies on the market, lower league football still struggles in anonymity, with clubs lacking fan and stakeholder support.

Some limitations of the research are that it has only looked at two variables of the entire CRM spectrum, and both have focused on online. At the same time, the variables have been analyzed only as self-standing, without making any correlations that could have measured the real utility of e-CRM. To assess the impact of CRM, future research could place online variables in connection with variables such as response rate or stadium visit. 


\section{References}

Ahearne, M., Hughes, D.E., Schillewaert, N. (2007): "Why sales reps should welcome information technology: Measuring the impact of CRM-based IT on sales effectiveness", International Journal of Research in Marketing, 24(4), 336-349.

Bruhn, M., Schnebelen, S., Schäfer, D. (2014), "Antecedents and consequences of the quality of e-customer-to-customer interactions in B2B brand communities", Industrial Marketing Management, 43(1), 164-176.

Bügel, M.S., Verhoef, P.C., Buunk, A.B. (2011), "Customer intimacy and commitment to relationships with firms in five different sectors: Preliminary evidence", Journal of Retailing and Consumer Services, . 18(4), 247-258.

Cambra-Fierro, J., Pérez, L., Grott, E. (2017), "Towards a co-creation framework in the retail banking services industry: Do demographics influence?", Journal of Retailing and Consumer Services, 34(1), 219-228.

Clemes, M.D, Brush, G.J., Collins, M.J. (2011), "Analysing the professional sport experience: A hierarchical approach", Sport Management Review, 14(4), 370388.

Galuszka, P. (2015), "New Economy of Fandom", Popular Music and Society, 38(1), 2543.

Ghazian, A., Hossaini, M.H., Farsijani, H. (2016), "The Effect of Customer Relationship Management and its Significant Relationship by Customers' Reactions in LG Company", Procedia Economics and Finance, 36, 42-50.

Gide, E., Riad Shams, S.M. (2011), "The use of e-CRM database to promote a valuebreeding bond network: the case of Hawthorn football club of Australian rules", Procedia Computer Science, 3(2011), 1083-1088.

Karakostas, B., Kardaras, D., Papathanassiou, E. (2005), „The state of CRM adoption by the financial services in the UK: an empirical investigation", Information \& Management, 42(6), 853-863.

Labrecque, L.I. (2014), "Fostering Consumer-Brand Relationships in Social Media Environments: The Role of Parasocial Interaction", Journal of Interactive Marketing, 28(2), 134-148.

Lee, Y., Kwon, O. (2011), "Intimacy, familiarity and continuance intention: An extended expectation-confirmation model in web-based services", Electronic Commerce Research and Applications, 10(3), 342-357.

Niemimaa, M. (2017), "Information systems continuity process: Conceptual foundations for the study of the "social"“", Computers \& Security, 65, 1-13.

Nyadzayo, M.W. and Khajehzadeh, S. (2016), "The antecedents of customer loyalty: A moderated mediation model of customer relationship management quality and brand image", Journal of Retailing and Consumer Services, 30, 262-270.

Pries, C., Stone, M. (2004), "Managing CRM implementation with consultants-CRM or change management?", Journal of Change Management, 4(4), 351-370.

Robinson, T. (2012), "Dyed in the wool? An empirical note on fan loyalty", Applied Economics, 44(8), 979-985.

San-Martín, S., Jiménez, N.H., López-Catalán, B. (2016). “The firms benefits of mobile CRM from the relationship marketing approach and the TOE model", Spanish Journal of Marketing - ESIC, 20(1), 18-29. 
Song T.H., Kim, S.Y., Kim, J.Y. (2016), "The dynamic effect of customer equity across firm growth: The case of small and medium-sized online retailers", Journal of Business Research, 69(9), 3755-3764.

Wang E.T.G., Hu, H., Hu, P. J.-H. (2013), "Examining the role of information technology in cultivating firms' dynamic marketing capabilities", Information \& Management, 50(6), 336-343.

PICBE | 719

Zablah, A.R., Bellenger, D.N., Johnston, W.J. (2004), "An evaluation of divergent perspectives on customer relationship management: Towards a common understanding of an emerging phenomenon", Industrial Marketing Management, 33(6), 475-489.

Zhang, M., Zhao, X., Voss, C., Zhu, G. (2016), “Innovating through services, co-creation and supplier integration: Cases from China", International Journal of Production Economics, 171(Part 2), 289-300. 